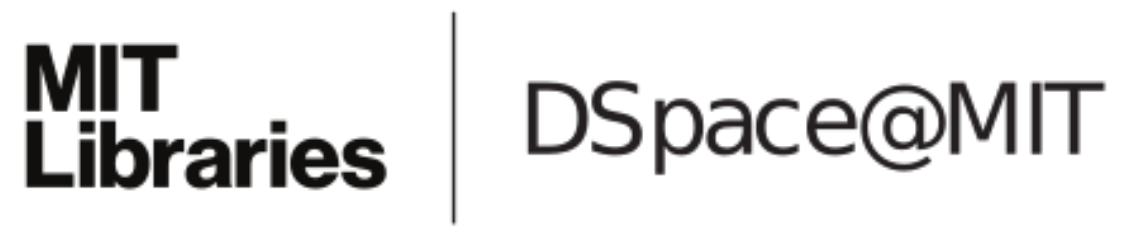

\author{
MIT Open Access Articles
}

Rapid Wolff-Kishner reductions in a silicon carbide microreactor

The MIT Faculty has made this article openly available. Please share how this access benefits you. Your story matters.

Citation: Newman, Stephen G., Lei Gu, Christoph Lesniak, Georg Victor, Frank Meschke, Lahbib Abahmane, and Klavs F. Jensen. "Rapid Wolff-Kishner Reductions in a Silicon Carbide Microreactor." Green Chemistry 16, no. 1 (2013): 176.

As Published: http://dx.doi.org/10.1039/c3gc41942h

Publisher: Royal Society of Chemistry

Persistent URL: http://hdl.handle.net/1721.1/93163

Version: Author's final manuscript: final author's manuscript post peer review, without publisher's formatting or copy editing

Terms of use: Creative Commons Attribution-Noncommercial-Share Alike 


\title{
Rapid Wolff-Kishner Reductions in a Silicon Carbide Microreactor
}

\author{
Stephen G. Newman, ${ }^{a}$ Lei Gu, ${ }^{a}$ Christoph Lesniak, ${ }^{\mathrm{b}}$ Georg Victor, ${ }^{\mathrm{b}}$ Frank Meschke, ${ }^{\mathrm{b}}$ Lahbib Abahmane, \\ and Klavs F. Jensen*a
}

\author{
s Received (in $X X X, X X X)$ Xth $X X X X X X X X X 20 X X$, Accepted Xth XXXXXXXXX 20XX \\ DOI: 10.1039/b000000x
}

Wolff-Kishner reductions are performed in a novel silicon carbide microreactor. Greatly reduced reaction times and safer operation are achieved, giving high yields without requiring a large excess of hydrazine. The corrosion resistance of silicon carbide avoids the problematic reactor compatibility issues that arise when Wolff-Kishner reductions are done in glass or stainless steel reactors. With only 10 nitrogen gas and water as by-products, this opens the possibility of performing selective, large scale ketone reductions without the generation of hazardous waste streams.

\section{Introduction}

The Wolff-Kishner reaction is a classical method for reducing ketones and aldehydes to the corresponding alkanes. ${ }^{1}$ In general, 15 the transformation involves mixing the substrate with a stoichiometric amount of hydrazine to form water and an intermediate hydrazone that, in the presence of a strong base, liberates nitrogen gas to give the final product. While many procedures for performing Wolff-Kishner reductions exist, the 20 most common is the Huang-Minlon modification, where a high boiling solvent is used and the temperature of the reactor is gradually elevated over the course of several hours. ${ }^{2}$ The volatile water and, subsequently, hydrazine are thus removed from the reaction, driving the equilibrium towards the intermediate 25 hydrazone over the course of the temperature ramp. The final loss of $\mathrm{N}_{2}$ occurs only at the elevated temperature. As such, the reaction can be considered to take place over three steps equilibrium formation of the hydrazone under reflux, temperature ramp and distillation to remove water and hydrazine and to drive 30 the equilibrium towards the hydrazone, and irreversible thermal reduction (Scheme 1). This procedure has been reported on mole scale, for instance in the preparation of docosanedioic acid, ${ }^{3}$ or towards the synthesis of an imidazole API precursor from Merck $\&$ Co. ${ }^{4}$ Both processes required several hours of operation over 35 three stages and a large excess of hydrazine. The presence of large quantities of explosive, gaseous hydrazine in the batch reactor head space presents a major safety concern in the further scale-up of such processes.

Despite these reports, there are many challenges 40 encountered in the Wolff-Kishner reduction. For instance, dangerous anhydrous hydrazine may be required. ${ }^{5}$ Pre-formation and isolation of the hydrazone intermediate is sometimes necessary, making formation of azine by-products a significant issue. $^{6}$ From a scale-up point of view, there are many safety 45 hazards associated with accumulation of explosive gaseous hydrazine in the reactor headspace. Moreover, reactor compatibility can be problematic. Hydrazine decomposition can be catalyzed by metals, so contact with stainless steel should
Typical Wolff-Kishner reduction
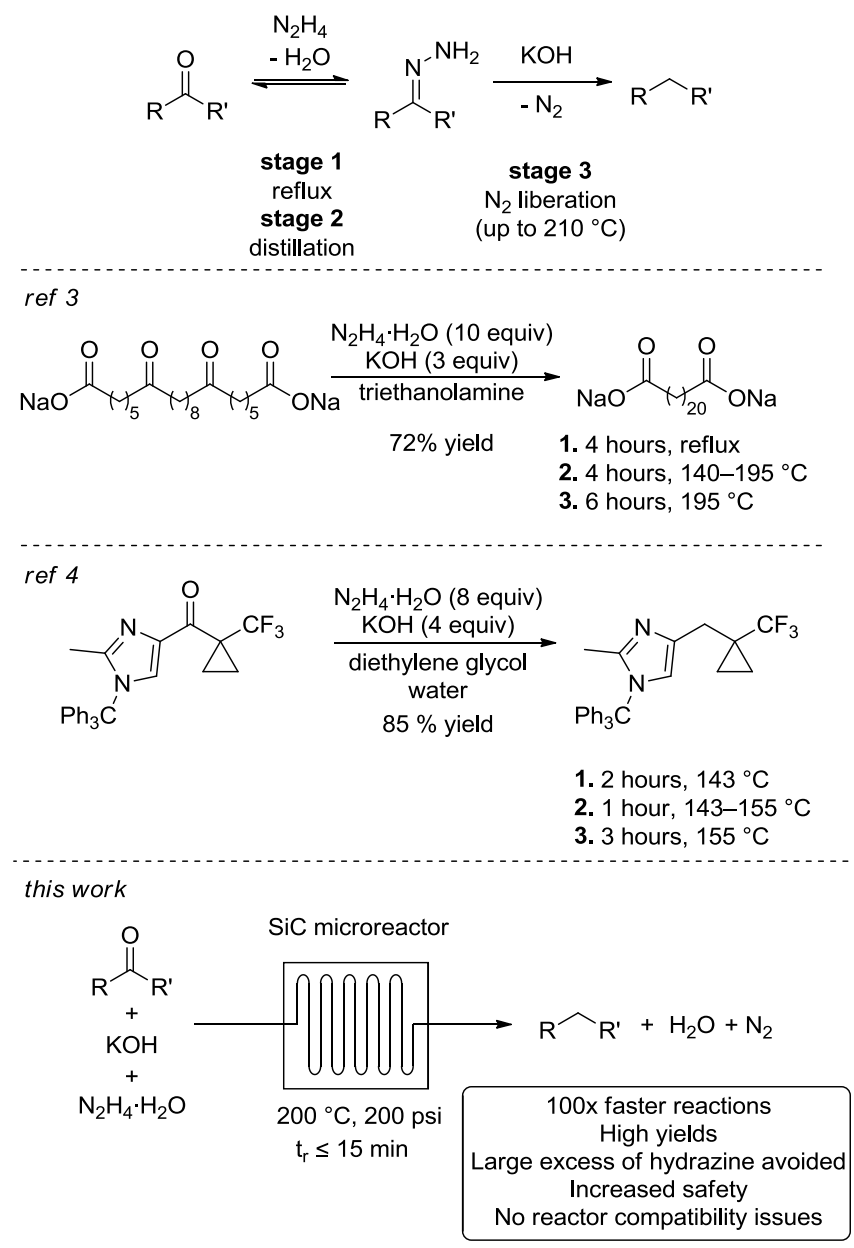

50 Scheme 1 Wolff-Kishner reductions in batch and flow. 
generally be avoided. ${ }^{7}$ Glass is also undesirable due to the ability of strong base to etch the surface at elevated temperatures. ${ }^{8}$

Many other methods for performing similar ketone and aldehyde reductions exist. The Clemmensen reduction, using 5 stoichiometric zinc, is a complimentary acidic reaction. ${ }^{9}$ The use of silanes or borohydrides along with a Lewis acid is also common. ${ }^{10}$ These and most other methods all have large waste streams, making them particularly environmentally unfriendly and costly on large scale. For example, researchers at Eli Lilly 10 recently performed a TFA-promoted triethylsilane reduction of a diaryl ketone to the corresponding methylene on 100 mol scale; however an alternative route was sought due to challenges associated with the disposal of the fluoride and silane waste. ${ }^{11}$ Catalytic reduction with hydrogen gas is the greenest method, but 15 suffers from limited scope and functional group compatibility. ${ }^{12}$ While the Wolff-Kishner reduction uses inexpensive hydrazine as a reducing agent and generates only water and nitrogen gas as waste products, alternative reduction methods are often chosen due to issues with high temperatures, high $\mathrm{pH}$, reactor 20 incompatibility, the need for multiple stages, and potential decomposition of hydrazine.

Flow chemistry can overcome many limitations of typical batch operation. ${ }^{13}$ From a safety standpoint, smaller reactors can often be used with improved heat transfer, reducing 25 issues with potential thermal runaway and explosions. Due to the ease with which temperature and pressure can be manipulated, a novel process window is introduced, giving access to a much wider range of reaction conditions. The enhanced mass and heat transfer, faster rates from the novel process window, continuous 30 collection of product, and option to operate multiple reactors simultaneously all contribute to the improved scalability of reactions done in flow. Lastly, the absence of head space in flow reactors mitigates the risk associated with the accumulation of explosive gases. We proposed many of the limitations of Wolff35 Kishner reactions could be overcome by operating in a continuous manner. However, most flow reactors are prepared out of base-sensitive silicon or glass, ${ }^{8}$ thermally sensitive polymer tubing, or steel that may react with hydrazine. ${ }^{14}$ To overcome these materials limitations, we designed a microreactor 40 prepared from sintered silicon carbide $(\mathrm{SiC})$.

\section{Results and Discussion}

$\mathrm{SiC}$ is a ceramic material with exceptional chemical compatibility, temperature stability, and thermal conductivity. These properties make it a useful component for demanding 45 applications such as in automobile brake discs and high temperature semiconductors. In chemical synthesis, Kappe and co-workers used a microwave vial made out of $\mathrm{SiC}$ to perform high temperature chemical reactions which would corrode typical Pyrex microwave vials. ${ }^{15}$ Industrial flow reactors constructed of ${ }_{50} \mathrm{SiC}$ have recently been commercialized by Boostec ${ }^{16}$ and $\mathrm{ESK}^{17}$ allowing access to otherwise 'forbidden' chemistries on large scale. Microreactors prepared out of robust ceramic materials are known; ${ }^{18}$ however, to our knowledge, none have been generally applicable for fine chemical synthesis. As such, we wanted to ${ }_{55}$ design a universally corrosion resistant microreactor constructed of $\mathrm{SiC}$ for the purpose of small scale reaction development. Such reactors would facilitate development of chemistries that may a)

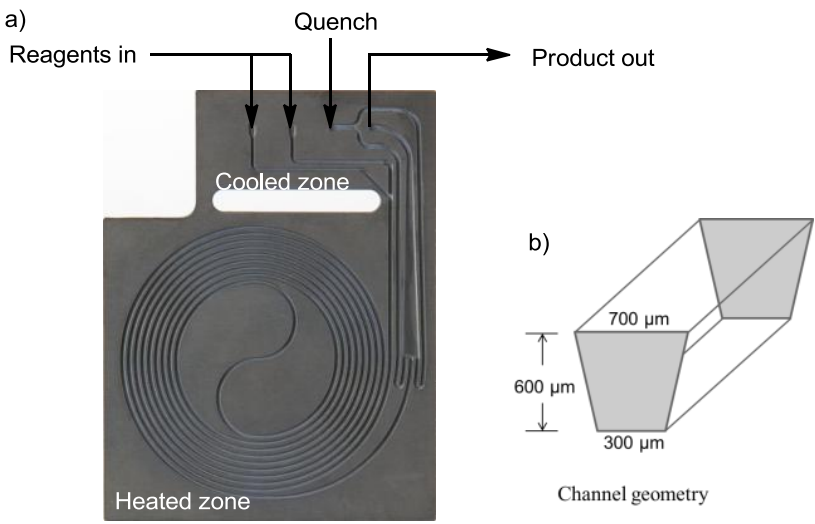

c)

d)

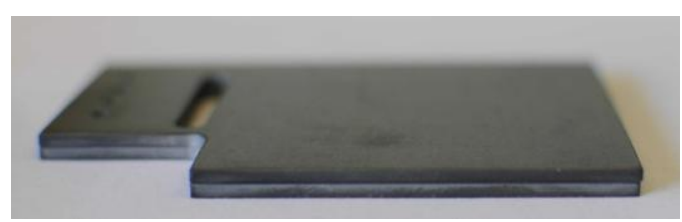

e)

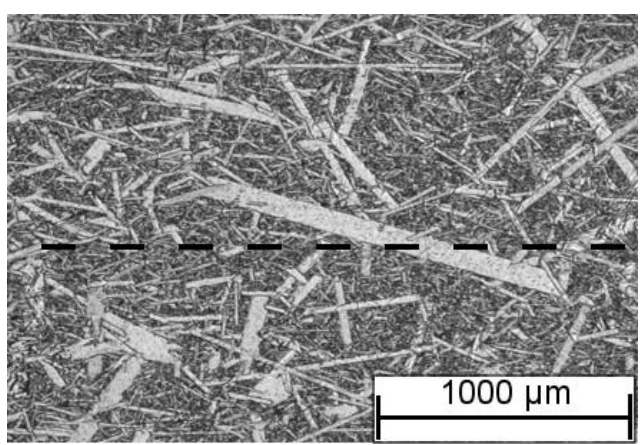

Fig. 1 a) An image of the bottom plate before diffusion bonding. b) An illustration of the trapezoid-shaped channels. c) The finished reactor. d) A bonding seam can be seen between the two plates. e) A cross-sectional 85 close-up of the interface after bonding and treatment with iron cyanide reveals the $\mathrm{SiC}$ crystals have grown from one plate to the other during diffusion, giving a seamless union in the interior. The dotted line illustrates where the two plates contacted each other prior to bonding. 
otherwise be impossible in traditional glass or metal reactors, without needing to commit the large amounts of material necessary to operate industrial scale $\mathrm{SiC}$ reactors

The design we chose was based on a silicon chip 5 previously developed in our lab. ${ }^{19}$ To ensure general applicability to a range of transformations, two inlets, a quench line, and an outlet were included (Figure 1a). This cooled inlet and outlet zone is thermally separated from a spiral heated zone by a halo etch. The reactor was produced by assembling a stack of two ${ }_{10}$ EKasic $^{\circledR}$ SiC plates with identical external dimensions and individual internal designs. The bottom plate has the manifold channels which were manufactured in the $\mathrm{SiC}$ green body using Nd:YAG scanning laser erosion machining. The trapezoid-shaped channels (Figure 1b) are in the hundreds of microns-range, giving 15 approximately $470 \mu \mathrm{L}$ total internal volume. The trapezoid crosssection of the channels is a result of the laser etching process; the edge shades the laser light making it difficult to produce completely rectangular cross-sections. The thermal insulation holes and all other features were milled in the sintered material ${ }_{20}$ post firing of each layer. Before being joined to a single-body, the top and bottom plates were precisely aligned to define the fluidic structures, i.e., inlet and outlet holes were aligned with channels. For diffusion bonding, the stacked plates were subjected to high temperature sintering at $\sim 1700{ }^{\circ} \mathrm{C}$ and 15 bar isostatic pressure 25 under inert atmosphere to give the monolithic reactor (Figure 1c). During this process the plates fused to form a strong bond. The outside of the reactor shows a small seam due to the low pressure applied on the edges during bonding (Figure 1d). However, a cross-sectional image of the inside of fully bonded reactor shows 30 no interface is evident where the two plates were joined (Figure 1e). Thus, the original stack of plates has become a monolithic piece of ceramic with homogenous mechanical proprieties. The microreactor channels are gas-tight and separated which is particularly important when hazardous substances are handled. 35 The final assembled reactor was successfully tested at 48 bar and $300{ }^{\circ} \mathrm{C}$ without failure.

With the new SiC microreactor in hand, we used benzophenone as a simple substrate for optimization of the Wolff-Kishner reduction. Parameters studied included pressure, 40 temperature, residence time, concentration in substrate, equivalents of hydrazine, equivalents of $\mathrm{KOH}$, and solvent. While many examples in the literature use a large excess of hydrazine, we proposed that the absence of reactor headspace and operation under pressure would allow efficient reactions to take place with

45 just 1.5 equivalents. With this limitation in mind, we found optimal conditions to be reaction at $200{ }^{\circ} \mathrm{C}$ and 200 psi backpressure with 3 equivalents of $\mathrm{KOH}$ at $0.8 \mathrm{M}$ concentration in diethyleneglycol monoethylether (carbitol) as the solvent. Under these conditions, an $83 \%$ yield of diphenylmethane could 50 be obtained with a remarkable residence time of just 5 minutes, ${ }^{20}$ corresponding to a production rate of $630 \mathrm{mg} / \mathrm{h}$ or $15.12 \mathrm{~g} /$ day with a excellent space-time yield of $61.9 \mathrm{~kg} / \mathrm{L} / \mathrm{h}$ (Table 1, entry 1). Operation at lower pressure, temperature, residence time, equivalence of hydrazine, or concentration were all found to 55 decrease the yield of the reaction (entries 2-6). Use of lower temperatures or fewer equivalents of $\mathrm{KOH}$ at $0.8 \mathrm{M}$ concentration led to clogging of the reactor due to buildup of insoluble azine. The effect of lowered base concentration on yield is apparent at
Table 1 Reaction optimization.

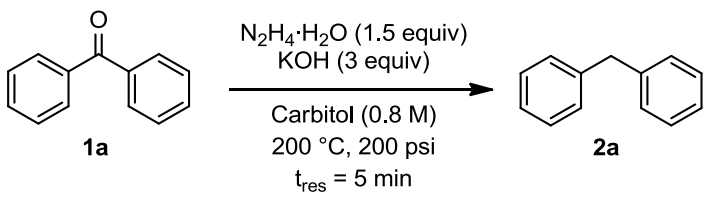

\begin{tabular}{llc}
\hline Entry & Change from standard conditions & Yield $^{\mathrm{a}}$ \\
\hline 1 & none & $83 \%$ \\
2 & $100 \mathrm{psi}$ & $44 \%$ \\
3 & $185^{\circ} \mathrm{C}^{\mathrm{b}}$ & $73 \%$ \\
4 & $\mathrm{t}_{\text {res }}=3 \mathrm{~min}$ & $71 \%$ \\
5 & 1.1 equiv $\mathrm{N}_{2} \mathrm{H}_{4} \cdot \mathrm{H}_{2} \mathrm{O}$ & $65 \%$ \\
6 & $0.4 \mathrm{M}$ & $65 \%$ \\
7 & $0.4 \mathrm{M}, 1.0$ equiv $\mathrm{KOH}$ & $33 \%$ \\
8 & $0.4 \mathrm{M}$, Diethylene glycol instead of carbitol & $36 \%$ \\
\hline \multirow{2}{*}{ Yield determined by GC with dodecane as internal } \\
standard. ${ }^{\mathrm{b}}$ Temperatures below $185{ }^{\circ} \mathrm{C}$ lead to \\
clogging of the reactor.
\end{tabular}

60

$0.4 \mathrm{M}$ (entry 7). The more common Wolff-Kishner solvent, diethylene glycol, was less effective at dissolving the reaction mixture, and could only be tested at $0.4 \mathrm{M}$, where it was found to be less effective than carbitol (entry 8). Other solvents such as 65 ethylene glycol and triethanolamine are highly viscosity and did not completely dissolve the reagents, making them poor choices for flow experiments.

Two remarkable aspects of the optimized results are apparent. Firstly, relatively few equivalents of hydrazine are 70 required. A typical batch experiment uses between 2 and 8 equivalents, adding additional costs and hazards, and complicating waste disposal. Secondly, the reaction time (5 min) is two orders of magnitude lower than in batch. The faster reaction is presumably due to the ability to operate safely in a 75 closed system under pressure which prevents hydrazine from boiling out of the reactor, and thus avoiding the need to perform the reaction in a series of stages. This likely has a further benefit of keeping all reaction components prior to the $\mathrm{N}_{2}$ liberation in equilibrium. In batch after the excess hydrazine has been 80 removed at elevated temperature, irreversible azine formation or reversion to starting material could occur. Azine formation was also evident in the flow experiment at 100 psi (Table 1, entry 2), presumably due to the relatively low concentrations of hydrazine in solution to drive the equilibrium towards the hydrazone.

85 To investigate the scope of the transformation, the reactivity of a range of aldehydes and ketones was explored (Table 2). Diphenylmethane could be isolated in good yield (entry 1). Further diluting hydrazine with water gives added safety from violent decomposition. Towards this end, an extra 3 90 equivalents of water relative to hydrazine (i.e. $31 \%$ aqueous hydrazine) were added, and a similar yield was obtained provided the residence time was lengthened. Electron-rich (entry 2) and electron-poor (entry 3) diaryl ketones could be reduced in high yield. 3-Chloro and -bromo substituents were also tolerated 95 (entries 4 and 5). Aryl alkyl (entries 6 and 7) and alkyl alkyl ketones (entry 8), as well as several aldehydes (entries 9-11) could also be reduced efficiently. 4-Bromobenzophenone was also attempted, but significant reduction of the $\mathrm{C}-\mathrm{Br}$ bond occurred and an accurate isolated yield could not be obtained. 100 Due to the differing solubilities of the starting materials and 
Table 2 Scope of the continuous Wolff-Kishner reduction. ${ }^{\text {a }}$

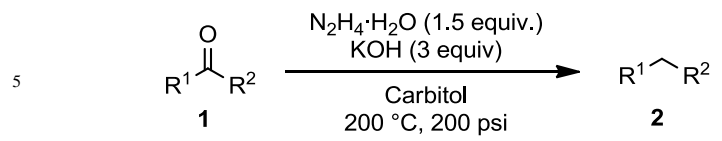

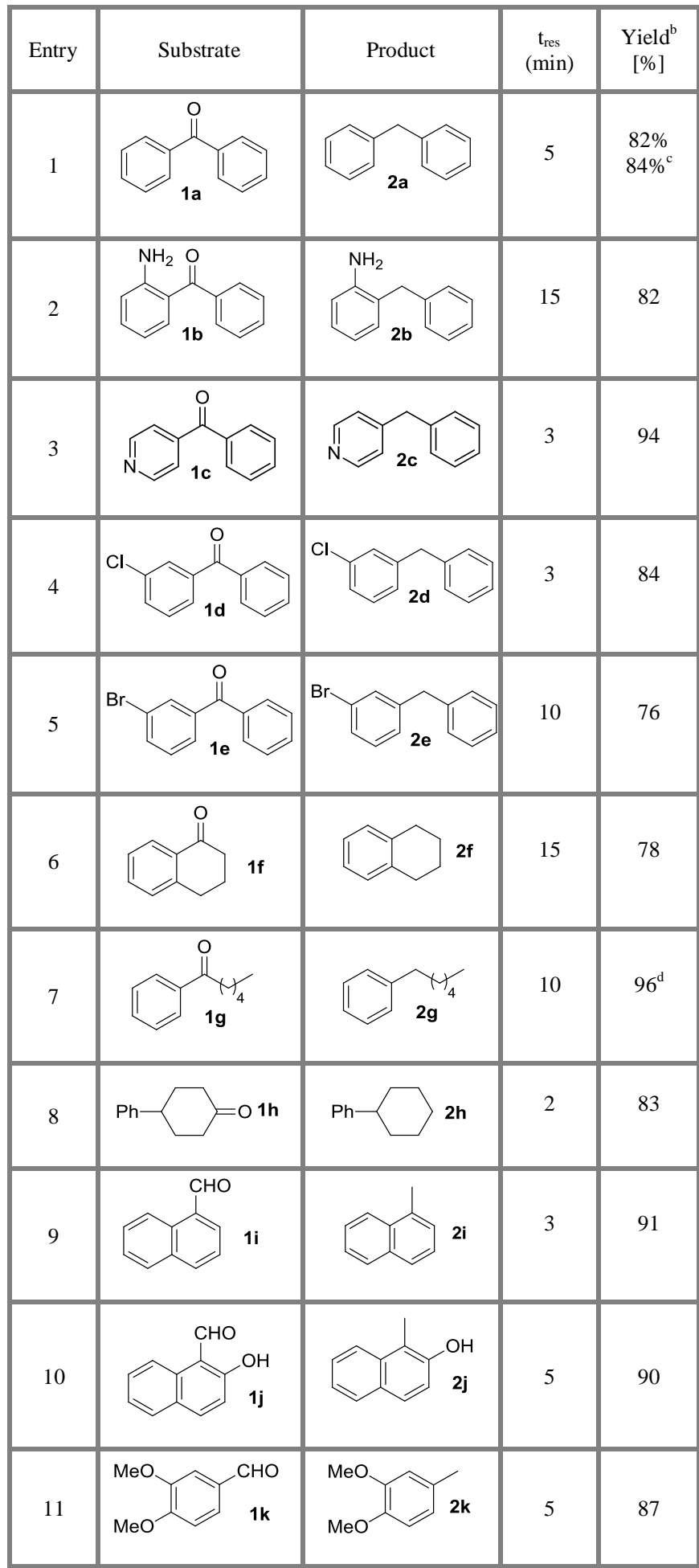

${ }^{\mathrm{a}}$ Typical reaction conditions: Substrate $\mathbf{1}(4 \mathrm{mmol}), \mathrm{N}_{2} \mathrm{H}_{4} \cdot \mathrm{H}_{2} \mathrm{O}(6 \mathrm{mmol})$, $\mathrm{KOH}(12 \mathrm{mmol}), 0.8 \mathrm{M}$ in carbitol, $200{ }^{\circ} \mathrm{C}$. Concentration varied per 10 entry. See supporting information. ${ }^{\mathrm{b}}$ Yield of isolated product. ${ }^{\mathrm{c}} 3$ Equiv additional $\mathrm{H}_{2} \mathrm{O}$ added. $\mathrm{t}_{\mathrm{res}}=10 \mathrm{~min} .{ }^{\mathrm{d}} 220^{\circ} \mathrm{C}$. intermediates, concentration was optimized separately for each example, and ranged from 0.1 to $0.8 \mathrm{M}$. The reactor could be run continuously for several hours without issue, and no corrosion 15 was evident over the course of our studies. The potential to perform such chemistries continuously on larger scale is thus very promising.

\section{Conclusions}

In conclusion, we have designed a new microreactor constructed 20 of $\mathrm{SiC}$, capable of withstanding exceptionally harsh reaction conditions. This was employed in performing continuous WolffKishner reductions, which could be completed quickly and safely. Compared with typical batch conditions, reaction times are decreased by up to two orders of magnitude. We believe our 25 microreactor will provide an important bridge between existing industrial scale flow reactors and small scale academic reaction development. The results obtained herein may facilitate WolffKishner reductions on previously inaccessible large scales due to the significant rate increase and the use of robust ceramic reactor 30 materials. Since no hazardous by-products are generated, this can provide an environmentally friendly alternative to more frequently employed hydride-, silane-, and metal-based methods.

\section{Experimental}

${ }_{35}$ General procedure: The substrate, $\mathrm{KOH}$ ( 3 equiv), and $4 \mathrm{~mL}$ of diethylene glycol monoethyl ether (carbitol) were combined in a $5 \mathrm{~mL}$ volumetric flask. The contents were placed in an ultrasonic cleaning bath and sonicated until the mixture became homogeneous. Hydrazine monohydrate (1.5 equiv) was added 40 and the flask was brought to $5 \mathrm{~mL}$ total volume by dropwise addition of carbitol. The reactor was connected to a 200 psi backpressure regulator at the outlet and brought to $200{ }^{\circ} \mathrm{C}$. The reacting solution was pumped through at $94 \mu \mathrm{L} / \mathrm{min}$ (for $\mathrm{t}_{\text {res }}=5$ min) using a Syrris Asia syringe pump with $500 / 250 \mu \mathrm{L}$ glass 45 syringes. The second inlet and quench line were plugged. After waiting for the reactor to reach steady state ( $\sim 3$ residence times), a sample vial was placed at the outlet and the product was collected for $\sim 2$ residence times. The sample was worked up and purified by flash column chromatography. Further details on the 50 apparatus, variations in specific examples, and workup procedure can be found in the Supporting Information.

\section{Acknowledgements}

${ }_{55} \mathrm{We}$ thank the Novartis-MIT Center for Continuous Manufacturing for support of this work. S.G.N. thanks the Natural Sciences and Engineering Research Council of Canada (NSERC) for financial support in the form of a postdoctoral fellowship.

\section{${ }_{60}$ Notes and references}

\author{
${ }^{a}$ Department of Chemical Engineering \\ Massachusetts Institute of Technology \\ 77 Massachusetts Ave., Cambridge MA 02139 (USA)
}


Fax: (+1) 617-258-8992; Tel: XX XXXX XXXX; E-mail:

kfiensen@mit.edu

${ }^{b}$ Technology \& Innovation department at ESK

ESK Ceramics GmbH \& Co. KG

5 Max-Schaidhauf-Straße 25

87437 Kempten, Germany

$\dagger$ Electronic Supplementary Information (ESI) available: Experimental details and NMR spectra. See DOI: 10.1039/b000000x/

10

1 a) D. Todd, Org. React., 1948, 4, 378; b) R. O. Hutchins and M. K. Hutchins in Comprehensive Organic Synthesis (Eds: B. M. Trost, I. Fleming), Pergamon Press: New York, 1991, Vol. 8, p. 327; c ) N. Kishner, J. Russ. Chem. Soc., 1911, 43, 582; d) L. Wolff, Justus

15 Liebigs Ann. Chem., 1912, 394, 86.

2 Huang-Minlon, J. Am. Chem. Soc. 1946, 68, 2487.

3 S. Hünig, E. Lücke, W. Brenniger, F. E. Mumford, E. A. LaLancette, W. J. Middleton and B. C. McKusick, Org. Syn., 1963, 43, 34.

4 J. T. Kuethe, K. G. Childers, Z. Peng, M. Journet and G. R. 20 Humphrey, Org. Process Res. Dev., 2009, 13, 576.

5 D. H. R. Barton, D. A. J. Ives and B. R. Thomas, J. Chem. Soc., 1955, 2056.

6 D. J. Cram, M. R. V. Sahyun and G. R. J. Know, J. Am. Chem. Soc., 1962, 84, 1734; b) M. F. Grundon, H. B. Henbest and M. D. Scott, J. Chem. Soc., 1963, 1855.

7 J.-P. Schirmann and P. Bourdauducq, "Hydrazine" in Ullmann's Encyclopedia of Industrial Chemistry, Wiley-VCH, Weinheim, 2002.

8. For example, silicon 100 is etched at a rate of $246 \mu \mathrm{m} /$ hour in $20 \%$ $\mathrm{KOH}$ at $100{ }^{\circ} \mathrm{C}$. While the presence of alcohol solvent slows this rate

30 down, the etch rate rapidly increases with temperature with an approximate activation energy of $\mathrm{E} / \mathrm{R}=7000 \mathrm{~K}$. At $200{ }^{\circ} \mathrm{C}$ the etch rate is $\sim 10 \mathrm{~mm} / \mathrm{h}$. Given the channel sizes of a typical silicon microreactor are several hundred $\mu \mathrm{m}$, the chemical environment will rapidly destroy the channel walls. See: H. Seidel, L. Csepregi, A.

35 Heuberger and H. Baumgärtel, J. Electrochem. Soc., 1990, 137, 3612. 9 E. Clemmensen. Chem. Ber. 1914, 47, 681.

10 a) D. Mitchell, K. P. Cole, P. M. Pollock, D. M. Coppert, T. P. Burkholder and J. R. Clayton, Org. Process Res. Dev., 2012, 16, 70; b) S. Chandrasekhar, C. R. Reddy and B. N. Babu, J. Org. Chem., 2002, 67, 9080; c) D. M. Ketcha, B. A. Lieurance, D. F. J. Homan and G. W. Gribble, J. Org. Chem., 1989, 54, 4350; d) I. Smonou, Tetrahedron Lett., 1994, 35, 2071.

11 a) D. Mitchell, K. P. Cole, P. M. Pollock, D. M. Coppert, T. P. Burkholder and J. R. Clayton, Org. Process Res. Dev., 2012, 16, 70.

45 b) A. N. Campbell, K. P. Cole , J. R. Martinelli, S. A. May, D. Mitchell, P. M. Pollock and K. A. Sullivan, Org. Process Res. Dev., 2013, 17, 273.

12 For recent examples, see: a) M. A. Alotaibi, E. F. Kozhevnikova and I. V. Kozhevnikov, Chem. Commun., 2012, 48, 7194; b) X. Xu, Y. Gong, P. Zhang, H. Li, Y. Wang, J. Am. Chem. Soc. 2012, 134, 16987; c) J. G. Stevens, R. A. Bourne, M. V. Twigg and M. Poliakoff, Angew. Chem. Int. Ed., 2010, 49, 8856; d) T. S. Hansen, K. Barta, P. T. Anastas, P. C. Ford and A. Riisager, Green Chem., 2012, 14, 2457.

5513 For recent overviews, see: a) J.-i. Yoshida in Flash Chemistry. Fast Organic Synthesis in Microsystems, Wiley-Blackwell, 2008; b) C. Wiles and P. Watts in Micro Reaction Technology in Organic Synthesis, CRC Press, 2011; c) S. G. Newman and K. F. Jensen, Green Chem., 2013, 15, 1456; d) B. P. Mason, K. E. Price, J. L. Steinbacher, A. R. Bogdan and D. T. McQuade, Chem. Rev. 2007, 107, 2300; e) C. Wiles and P. Watts, Green Chem. 2012, 14, 38; f) J. Wegner, S. Ceylan and A. Kirschning, Adv. Synth. Catal. 2012, 354, 17.

14 For examples on the safe use of hydrazine in flow, see a) A. DeAngelis, D.-H. Wang and S. L. Buchwald, Angew. Chem. Int. Ed., 2013, 52, 3434; b) T.-H. Yoon, S.-H. Park, K.-I. Min, X. Zhang, S. J. Haswell and D.-P. Kim, Lab Chip, 2008, 8, 1454; c) C. Wiles, P. Watts and S. J. Haswell, Org. Process Res. Dev., 2004, 8, 28; d) E. Garcia-Egido, V. Spikmans, S. Y. F. Wong and B. H. Warrington,
2012, 14, 800; f) D. Cantillo, M. Baghbanzadeh and C. O. Kappe, Angew. Chem. Int. Ed., 2012, 51, 10190.

15 B. Gutmann, D. Obermayer, B. Reichart, B. Prekodravac, M. Irfan, J. M. Kremsner and C. O. Kappe, Chem. Eur. J., 2010, 16, 12182.

7516 S. Elgue, A. Conte, C. Gourdon and Y. Bastard, Chim. Oggi, 2012, 30, 18.

17 L. Abahmane, "EKasic ${ }^{\circledR}$ modular flow reactor systems for chemical production under severe conditions." 4th Symposium on Continuous Flow Reactor Technology for Industrial Applications, Lisbon (Portugal), September 26-27, 2012.

18 a) Christian, M. Mitchell, D. P. Kim and P. J. A. Kenis, J. Catal., 2006, 241, 235; b) R. Knitter, D. Gohring, P. Risthaus and J. Hausselt, Microsyst. Technol., 2001, 7, 85; c) F. Meschke, G. Riebler, V. Hessel, J. Schürer and T. Baier, Chem. Eng. Technol., 2005, 28, 465; d) K. Jain, C. Wu, S. V. Atre, G. Jovanovic, V. Narayanan, S. Kimura, V. Sprenkle, N. Canfield and S. Roy, Int. J. Appl. Ceram. Technol., 2009, 6, 410.

19 R. L. Hartman, J. R. Naber, N. Zaborenko, S. L. Buchwald and K. F. Jensen, Org. Process Res. Dev., 2010, 14, 1347.

9020 The stated residence time is defined as volume of the reactor divided by the feed rate of reactants. Since nitrogen gas is generated and some thermal expansion of the heated solution is likely, the actual time that the reactants spend in the reactor will be lower. 